\title{
A meta-analysis of the factors influencing development rate variation in Aedes aegypti (Diptera: Culicidae)
}

\author{
Jannelle Couret ${ }^{1 *}$ and Mark Q Benedict ${ }^{2}$
}

\begin{abstract}
Background: Development rates of Aedes aegypti are known to vary with respect to many abiotic and biotic factors including temperature, resource availability, and intraspecific competition. The relative importance of these factors and their interactions are not well established across populations. We performed meta-analysis on a dataset of development rate estimates from 49 studies.

Results: Meta-analytic results indicated that the environmental factor of temperature is sufficient to explain development rate variability in Ae. aegypti. While diet and density may greatly impact other developmental phenotypes, these results suggest that for development rate these factors should never be considered to the exclusion of temperature. The effect of temperature on development rate is not homogenous or constant. The sources of heterogeneity of the effect of temperature are difficult to analyze due to lack of consistent reporting of larval rearing methods.

Conclusions: Temperature is the most important ecological determinant of development rate in Ae. aegypti, but its effect is heterogeneous. Ignoring this heterogeneity is problematic for models of vector population and vector-borne disease transmission.
\end{abstract}

Keywords: Mosquito, Meta-analysis, Temperature, Development, Diet, Density, Development rate, Survival

\section{Background}

The effect of temperature on growth has been studied across a wide diversity of organisms [1-6]. Like all poikilotherms, the biochemical and physiological processes of insects depend on body temperature, and ambient environmental temperature has a profound effect on the metabolic rate and growth of insects. With short generation times and high fecundity, insects are convenient model species both in the laboratory and the field, as over a century of research establishes that temperature influences the duration and rate of development [7-16]. A main feature of this body of research is the emphasis on prediction of the timing of maturation $[17,18]$, body size $[19,20]$, and population dynamics [21-23]. However, with the benefits of simplicity and practicality of considering only temperature for predicting developmental

\footnotetext{
*Correspondence: jcouret@emory.edu

'Department of Biology, Emory University, 1510 Clifton Road NE, Atlanta, GA 30322, USA

Full list of author information is available at the end of the article
}

timing come the costs of ignoring other environmental and ecological factors of known importance such as resource availability, competition, and predation.

Particularly in insects of medical importance, such as mosquitoes that vector human pathogens, estimates of developmental characteristics and models of developmental timing are used to guide vector population control efforts [24]. In particular, controlling the population of the mosquito vector Aedes aegypti (Linnaeus) is critical to preventing dengue infection [25], as there is no vaccine or chemotherapeutic treatment [26]. In Ae. aegypti, insecticide resistance $[27,28]$ and continued progress with transgenic strains and their release [29] underscore the need to understand developmental phenotypes. Increasingly unpredictable climate patterns [30] motivate the study of development rate in response to varied environmental conditions [31,32].

Few studies have sought to determine importance of other conditions of the developmental environment relative to temperature to explain individual variation in 
development rate $[7,33]$. Plasticity of development rate has been demonstrated in many diverse taxa. In mosquitoes, developmental traits vary in response to gradients of abiotic and biotic factors such as diet [34-41], larval rearing density [24,42,43], fungal infection [44], nutrient quality [45,46], thermoperiodism [47], and presence of predators [48]. Inclusion of the variability in development rate with respect to factors other than temperature might improve the realism of models. However, temperature is often considered the main driver of development [49], and it is unclear whether other factors are necessary to adequately explain variation in development rate. We hypothesize that development rate is significantly influenced by several environmental factors apart from temperature and that the interaction of these factors is an important predictor of development rate variation.

To test these hypotheses in diverse environmental conditions, empirical data is needed that considers development rate 1) in response to multiple factors [50], 2) over a gradient, (i.e. 2 or more levels) of each environmental factor [17], and 3) across heterogeneous space [19]. Data of such a broad scope may be difficult to produce within one experiment or study. However, we may approach such a dataset by meta-analysis of a compilation of published estimates of development rate with respect to different environmental factors. In this manner, the phenotype of development rate in response to multiple environmental conditions can be assessed over a wider range of conditions and broader geographical bounds.

Ae. aegypti has been well-studied, as it vectors several human pathogens including yellow fever, dengue, and chikungunya, [51,52]. We conducted a meta-analysis of data from studies of the development of Ae. aegypti with an aim toward summarizing the impact of multiple environmental conditions on developmental duration, determining the relative importance of these factors, and evaluating their interactions. The conditions evaluated here include temperature, food concentration, food type, larval rearing density, geographic location, and latitude. The linear relationship between development rate and temperature was also evaluated across studies to test the hypothesis that it is a fixed characteristic of the species.

\section{Methods}

\section{Literature search}

For the literature search and meta-analysis we adhered to PRISMA guidelines. We searched online databases for peer-reviewed research papers in December of 2011 pertaining to Ae. aegypti development. Of the two forms of Ae. aegypti, Ae. a. formosus, was not included because of known differences in ecology [53], behavior [54], and spatial distribution [55] with limited gene flow between forms [56]. The list of databases searched along with keywords and the number of papers included from each source is summarized in supplementary materials (Table S1). The inclusion criteria were as follows. Studies had to report i) the larval rearing temperature, ii) the development time of mosquitoes from hatch to pupation or hatch to emergence in hours or days (data could be in either tabular or graphical format and graphical data were digitally extracted with PlotDigitizer; copyright 2000-20011, Joseph A. Huwaldt), iii) the number of replicates, and iv) the number of larvae included for each estimate. In order to accomplish a meta-analysis, datasets must have similar experimental designs [57], and we focused on studies that estimated development time with respect to temperature. We made every effort to include as many environmental factors as possible. Whenever reported we also included other methodological information of diet level (in milligrams of food per larva per day), diet type (main ingredient), larval rearing density (number of larvae per milliliter of water), photoperiod, and global position coordinates of the study or, when available and specified, strain origin (Table 1). Studies with transgenic strains were also included with "transgenic" added as another factor. For studies of laboratory strains of mosquitoes, we used the coordinates of the strain's location of origin. These data were compiled into a Microsoft Excel (Redmond, Washington: Microsoft 2011) spreadsheet and are available in supplementary materials and from the corresponding author.

\section{Meta-analysis}

We used two meta-analytic approaches for these data. In our first approach we evaluated estimates of development time from hatch to pupation and development time from hatch to emergence using a mixed linear regression model [105] "nlme" [106] implemented in R statistical software v3.0.2 [107]. These two dependent variables were analyzed separately. Factors evaluated included temperature, larval rearing density, diet level (mg/larvae/day), latitude of strain origin, photoperiod, and publication. For a study to be included in the mixed linear regression model at least one environmental factor had to be reported along with the estimate of development time (i.e. at least one temperature, larval rearing density, or diet level). The variable of sex was not considered for hatch to emergence in this portion of the analysis as many studies reported values for only females or did not report sex at all. Publication author was considered a random factor in our analysis as our primary interest was the in the effects of other variables across studies. Parameters were eliminated using backward model selection and a minimization of the Akaike Information Criterion (AIC) and BIC (Bayesian Information Criterion). Both criteria impose a penalty for increasing the number of parameters in a model. A model with 
Table 1 Studies included in the meta-analysis of Ae. aegypti development

\begin{tabular}{|c|c|c|c|c|c|c|c|c|c|c|}
\hline Temp & $\begin{array}{c}\text { Temp } \\
\text { gradient }\end{array}$ & Density & $\begin{array}{c}\text { Density } \\
\text { gradient }\end{array}$ & $\begin{array}{c}\text { Diet } \\
\text { (amt) }\end{array}$ & $\begin{array}{c}\text { Diet } \\
\text { gradient }\end{array}$ & $\begin{array}{c}\text { Diet } \\
\text { (type) }\end{array}$ & $\begin{array}{l}\text { Photo- } \\
\text { period }\end{array}$ & Latitude & Author \& Year & Journal \\
\hline$\checkmark$ & & $\checkmark$ & $\checkmark$ & & & $\checkmark$ & $\checkmark$ & Est. & Bargielowski et al. 2011 [58] & PLOS ONE \\
\hline$\checkmark$ & $\checkmark$ & $\checkmark$ & & $\checkmark$ & & $\checkmark$ & $\checkmark$ & $\checkmark$ & Farjana et al. 2012 [34] & Med. Vet. Entomol. \\
\hline$\checkmark$ & $\checkmark$ & $\checkmark$ & & $\checkmark$ & & $\checkmark$ & & $\checkmark$ & $\begin{array}{l}\text { Mohammed and } \\
\text { Chadee } 2011 \text { [59] }\end{array}$ & Acta Trop. \\
\hline$\checkmark$ & $\checkmark$ & & & & & $\checkmark$ & & $\checkmark$ & Padmanabha et al. 2011 [60] & Med. Vet. Entomol. \\
\hline$\checkmark$ & & $\checkmark$ & $\checkmark$ & & & $\checkmark$ & $\checkmark$ & Est. & Maciá 2009 [61] & Rev. Soc. Entomol. Argent. \\
\hline$\checkmark$ & & $\checkmark$ & $\checkmark$ & & & $\checkmark$ & $\checkmark$ & Est. & Reiskind and Lounibus 2009 [62] & Med. Vet. Entomol. \\
\hline$\checkmark$ & & $\checkmark$ & & $\checkmark$ & & $\checkmark$ & $\checkmark$ & $\checkmark$ & Tejerina et al. 2009 [63] & Acta Trop. \\
\hline$\checkmark$ & & $\checkmark$ & & $\checkmark$ & & $\checkmark$ & $\checkmark$ & $\checkmark$ & Beserra and Castro 2008 [64] & Neotrop. Entomol. \\
\hline$\checkmark$ & & $\checkmark$ & & & & $\checkmark$ & $\checkmark$ & $\checkmark$ & Chang et al. 2007 [65] & J. Med. Entomol. \\
\hline$\checkmark$ & $\checkmark$ & $\checkmark$ & & $\checkmark$ & & $\checkmark$ & $\checkmark$ & $\checkmark$ & Beserra et al. 2006 [66] & Neotrop. Entomol. \\
\hline$\checkmark$ & & $\checkmark$ & & $\checkmark$ & $\checkmark$ & $\checkmark$ & $\checkmark$ & $\checkmark$ & Arrivillaga and Barrera 2004 [67] & J. Vector. Ecol. \\
\hline$\checkmark$ & & $\checkmark$ & & $\checkmark$ & $\checkmark$ & $\checkmark$ & $\checkmark$ & Est. & Bedhomme et al. 2004 [68] & Proc. R. Soc. Lond. B. \\
\hline$\checkmark$ & & $\checkmark$ & & $\checkmark$ & & $\checkmark$ & $\checkmark$ & Est. & Irvin et al. 2004 [69] & PNAS \\
\hline$\checkmark$ & & $\checkmark$ & $\checkmark$ & $\checkmark$ & $\checkmark$ & $\checkmark$ & & Est. & Agnew et al. 2002 [43] & Ecol. Entomol. \\
\hline$\checkmark$ & $\checkmark$ & $\checkmark$ & & $\checkmark$ & & $\checkmark$ & $\checkmark$ & $\checkmark$ & Kamimura et al. 2002 [70] & Med. Entomol. Zool. \\
\hline$\checkmark$ & & $\checkmark$ & & $\checkmark$ & & $\checkmark$ & $\checkmark$ & Est. & Lounibus et al. 2002 [71] & J. Vector. Ecol. \\
\hline$\checkmark$ & $\checkmark$ & $\checkmark$ & & & & $\checkmark$ & & Est. & Tsuda and Takagi 2001 [72] & Environ. Entomol. \\
\hline$\checkmark$ & $\checkmark$ & $\checkmark$ & & $\checkmark$ & & $\checkmark$ & $\checkmark$ & $\checkmark$ & Tun-Lin et al. 2000 [73] & Med. Vet. Entomol. \\
\hline$\checkmark$ & & & & & & & & Est. & Costero et al. 1999 [74] & J. Med. Entomol. \\
\hline$\checkmark$ & & $\checkmark$ & $\checkmark$ & & & $\checkmark$ & $\checkmark$ & Est. & Silva and Silva 1999 [75] & Rev. Soc. Bras. Med. Trop. \\
\hline$\checkmark$ & $\checkmark$ & & & & & & & Est. & Thu et al. 1998 [76] & SE Asian Trop. Med. \\
\hline$\checkmark$ & $\checkmark$ & $\checkmark$ & & $\checkmark$ & & $\checkmark$ & $\checkmark$ & Est. & Becnel and Undeen 1992 [77] & J. Invertebr. Pathol. \\
\hline$\checkmark$ & $\checkmark$ & $\checkmark$ & & & & $\checkmark$ & $\checkmark$ & Est. & Rueda et al. 1990 [78] & J. Med. Entomol. \\
\hline$\checkmark$ & & $\checkmark$ & & $\checkmark$ & & $\checkmark$ & $\checkmark$ & Est. & Ho et al. 1989 [79] & J. Med. Entomol. \\
\hline$\checkmark$ & & $\checkmark$ & $\checkmark$ & $\checkmark$ & $\checkmark$ & $\checkmark$ & $\checkmark$ & Est. & Russell 1986 [80] & Aust. J. Zool. \\
\hline$\checkmark$ & & & & & & $\checkmark$ & $\checkmark$ & Est. & Soekiman et al. 1984 [81] & ICMR Ann. \\
\hline$\checkmark$ & & $\checkmark$ & $\checkmark$ & $\checkmark$ & & $\checkmark$ & $\checkmark$ & & Dye 1982 [82] & Ecol. Entomol. \\
\hline$\checkmark$ & & $\checkmark$ & & $\checkmark$ & & $\checkmark$ & & Est. & Saul et al. 1980 [83] & Am. Midl. Nat. \\
\hline$\checkmark$ & $\checkmark$ & & & & & $\checkmark$ & & Est. & Gilpin and McClelland 1979 [84] & Fortschr. Zool. \\
\hline$\checkmark$ & & $\checkmark$ & & & & $\checkmark$ & & Est. & Dadd et al. 1977 [85] & Mosq. News \\
\hline$\checkmark$ & $\checkmark$ & $\checkmark$ & & & & & & Est. & Lachmajer and Hien 1975 [86] & Inst.t Med. Morskiej I Trop. \\
\hline$\checkmark$ & & $\checkmark$ & & & & $\checkmark$ & & Est. & Ameen and Moizuddin 1973 [87] & Dacca Univ. Stud. \\
\hline$\checkmark$ & & $\checkmark$ & & $\checkmark$ & & $\checkmark$ & & Est. & Moore and Whitacre 1972 [88] & Ann. Entomol. Soc. Am. \\
\hline$\checkmark$ & & & & & & & & Est. & Southwood et al. 1972 [89] & Bull. World Health Organ. \\
\hline$\checkmark$ & & $\checkmark$ & & & & & & Est. & Rosay 1972 [90] & Mosq. News \\
\hline$\checkmark$ & & & & & & & & & Nayar 1970 [91] & J. Med. Entomol. \\
\hline$\checkmark$ & $\checkmark$ & & & & & $\checkmark$ & & Est. & McCray et al. 1970 [92] & J. Invertebr. Pathol. \\
\hline$\checkmark$ & & $\checkmark$ & & & & $\checkmark$ & & Est. & Keirans 1969 [93] & Mosq. News \\
\hline$\checkmark$ & & $\checkmark$ & $\checkmark$ & $\checkmark$ & $\checkmark$ & $\checkmark$ & $\checkmark$ & Est. & Moore and Fisher 1969 [94] & Ann. Entomol. Soc. Am. \\
\hline$\checkmark$ & & $\checkmark$ & & $\checkmark$ & $\checkmark$ & $\checkmark$ & & Est. & Peters et al. 1969 [95] & Mosq. News \\
\hline$\checkmark$ & & $\checkmark$ & & & & $\checkmark$ & & Est. & Brust 1968 [96] & J. Econ. Entomol. \\
\hline$\checkmark$ & $\checkmark$ & $\checkmark$ & & & & $\checkmark$ & & Est. & Keirans and Fay 1968 [97] & Mosq. News \\
\hline$\checkmark$ & $\checkmark$ & $\checkmark$ & $\checkmark$ & $\checkmark$ & $\checkmark$ & $\checkmark$ & & Est. & Wada 1965 [98] & Quaestiones entomologicae \\
\hline
\end{tabular}


Table 1 Studies included in the meta-analysis of Ae. aegypti development (Continued)

\begin{tabular}{|c|c|c|c|c|c|c|c|}
\hline$\checkmark$ & & $\checkmark$ & $\checkmark$ & $\checkmark$ & Est. & Lea 1963 [99] & J. Insect. Physiol. \\
\hline \multirow[t]{2}{*}{$\checkmark$} & $\checkmark$ & $\checkmark$ & $\checkmark$ & & $\checkmark$ & Ofuji 1963 [100] & $\begin{array}{l}\text { B. Res Inst. Endem. Nagasaki } \\
\text { Univ. }\end{array}$ \\
\hline & & & & & & Christophers 1960 [101] & Cambridge University Press \\
\hline$\checkmark$ & $\checkmark$ & $\checkmark$ & & $\checkmark$ & Est. & Bar-Zeev 1958 [102] & B. Entomol. Res. \\
\hline$\checkmark$ & $\checkmark$ & & & & & Headlee 1940 [103] & J. Econ. Entomol. \\
\hline$\checkmark$ & $\checkmark$ & & & $\checkmark$ & & Headlee 1941 [104] & J. Econ. Entomol. \\
\hline
\end{tabular}

Check marks indicate studies that have reported at least one value of the environmental conditions listed including temperature, diet (mg/larva/day), density (larvae/mL), or photoperiod. Gradient columns indicate whether the study considered three or more levels of the environmental condition. Latitude of origin was either reported (check mark) or estimated (Est.) based on the city of origin of the mosquito strain. Studies that considered transgenic strains are indicated in bold. Development rate estimates for transgenic strains were not included in the meta-analysis. A full bibliography is available in Additional file 1 : Table S2.

$\triangle \mathrm{AIC}=2$ and $\triangle \mathrm{BIC}=2$ or more units lower than any other model was considered the best [105].

In our second approach, we focused analysis on a temperature range for which development rate (1/development time) can be well approximated with a linear model. Development rates in Ae. aegypti are well approximated by a linear model within the temperature range from $14-31^{\circ} \mathrm{C}$ [84]. The linear model is described with the following equation,

$$
y=B_{1} x+B_{0}
$$

where $y=1 /$ development rate, and $y$ is regressed on temperature, $\mathrm{x}$. The parameter $B_{O}$ represents the developmental zero and $B_{1}$ is a constant for the cumulative effective of temperature, generally reported as $K[108,109]$. When parameter estimates were not directly reported, linear models were run in the open source package $R$ version 2.14.0 ( $R$ Development Core Team 2012). Linear models in this second meta-analytic approach were only conducted on data from studies that estimated development rate over three or more temperatures in order to allow for a regression analysis. For meta-analysis, parameter estimates of $B_{1}$ and $B_{O}$ were each used as effect measures, and were weighted by the number of replicates per experiment in a study. We tested the hypotheses that cumulative effect of temperature $(K)$ and developmental zero $(t)$ are constant properties of a mosquito strain using a test of total heterogeneity, $\mathrm{Q}_{\mathrm{T}}$, with Hedge's estimator, a standardized difference method for comparing effect measures [57,110]. Next, we used a linear mixed effects model to determine the variables that best explained this heterogeneity including publication, diet, larval rearing density, and latitude of strain origin. We then tested for residual heterogeneity, $\mathrm{Q}_{\mathrm{E}}$ $[57,110]$. For this portion of the analysis we were able to include the variable of sex due to greater reporting in this subset of studies. Sex was considered with three categories: male, female, and both.

\section{Results}

Based on a literature search of 11 online databases using search terms including Aedes aegypti, temperature, diet, larval rearing density, and development rate, we found 27,559 articles, from which 48 journal publications and one book chapter fit the inclusion criteria (Table 1). From these, data on development rate were compiled for 66 populations of Ae. aegypti (references in Additional file 1: Table S2; dataset available upon request) spanning approximately $87^{\circ}$ of latitude (Figure 1). Among these studies, 39\% evaluated temperature across a gradient of 2 or more levels, and $77 \%$ of all reported one intraspecific rearing density whereas $18 \%$ considered larval rearing density gradients. Many studies reported food added ad libitum, but among the subset of studies that reported diet values, 25\% examined diet gradients. Photoperiod was reported in $45 \%$ of studies. Some studies were laboratory based and others were field-based or under semi-natural conditions. This facilitated the comparison of constant versus variable temperatures on development rate (Figure 2).

The type of diet was reported for 42 of 49 experiments, and of these studies 32 had a unique diet composition. Diets shared across multiple studies included brewer's yeast and Tetramin ${ }^{\circledR}$ Fish Food. Unique diets were combinations of these and various other sources including, but not limited to, rabbit food, dog food, pig chow, pig liver powder, beef liver powder, bacterial infusions, detritus, and unspecified larval broth. Inclusion of diet type led to over-parameterization of models and was dropped from the analysis as a factor due to the number of unique types.

Development time of larval stages, development time from hatch to emergence, and percent survival were compiled into a dataset for the first meta-analytic approach (Additional file 1: Table S2). Inclusion required an estimate of development rate of Ae. aegypti under at least one value of temperature, larval rearing density, or diet. The compiled dataset had 283 estimates of development time from hatch to pupation and 127 from hatch 

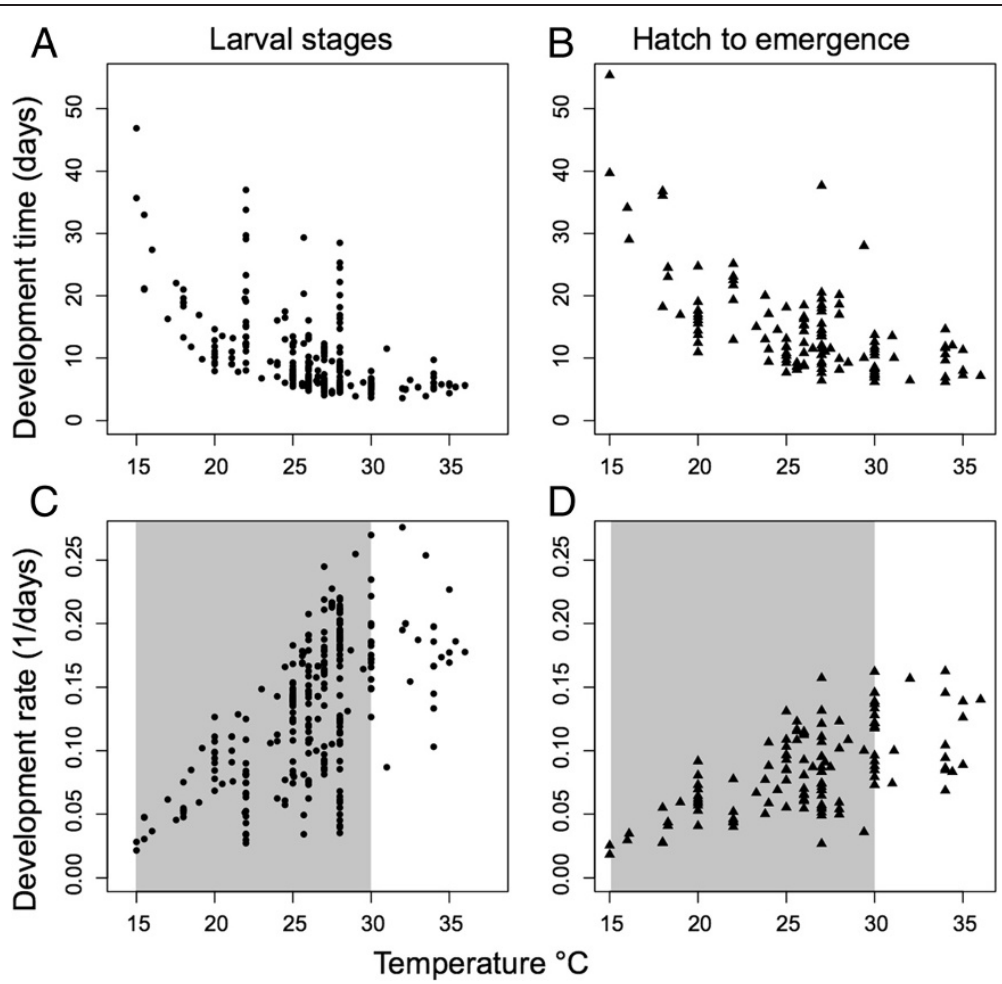

Figure 1 Compiled dataset of development time (days) and development rate (1/days) plotted against temperature for hatch to pupation, i.e. larval stages (A and C, respectively), and hatch to emergence (B and D respectively). Shaded gray bars show the subset of data used for linear models of development rate.

to emergence (Figure 1, panels A and B). Temperatures ranged from $14-37.8^{\circ} \mathrm{C}$. Development times were not normally distributed for larval stages (Shapiro-Wilk test, $\mathrm{W}=0.727, \mathrm{p}<0.0001$ ) or from hatch to emergence $(\mathrm{W}=0.7942, \mathrm{p}<0.0001)$, and therefore estimates were transformed into development rate in the form of the inverse of development time. Development rates were normally distributed for larval stages $(\mathrm{W}=0.9797, \mathrm{p}>$ $0.08)$ and hatch to emergence $(W=0.9532, p>0.1)$. Development rate showed a significant positive association with rearing temperature across all studies for larval stages $\left(B_{1}=0.008913, \mathrm{t}_{281}=13.50, \mathrm{p}<0.0001\right.$,
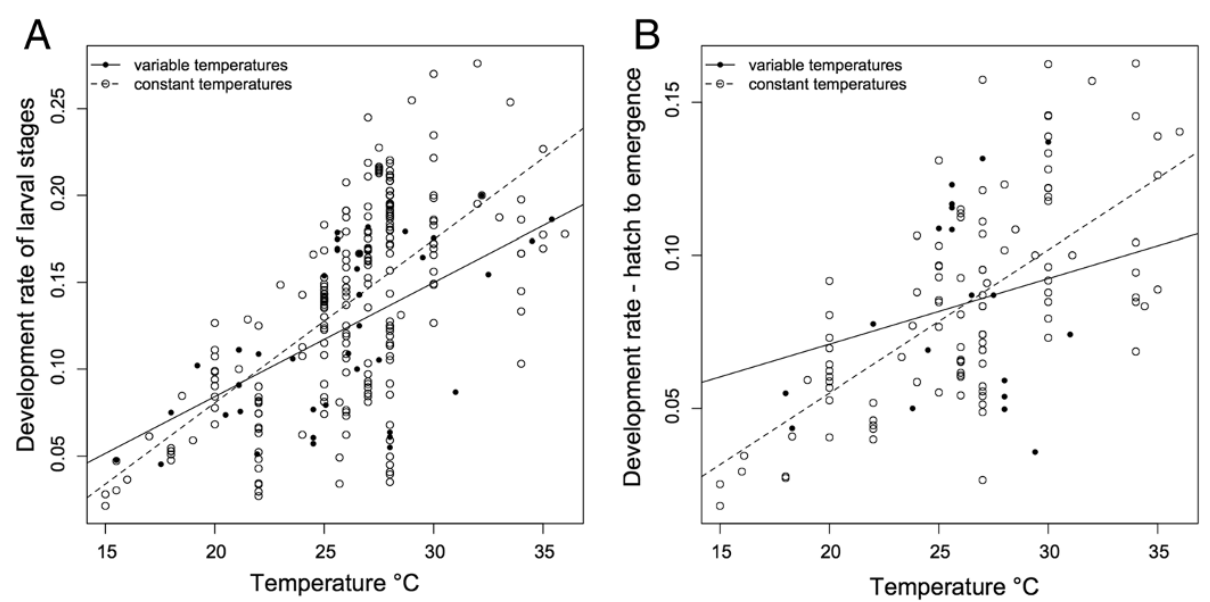

Figure 2 Development rate (inverse development time) estimates for (A) hatch to pupation, i.e. larval stages, and (B) hatch to emergence plotted against temperature. Character shape represents whether larvae were reared in constant or variable temperatures. Line type corresponds with character shape and lines indicate linear regression of development rate and temperature for constant and variable temperatures. 
$R^{2}=0.3782$; Figure 1, panel C). Similarly, the development rate from hatch to emergence is significantly associated with temperature $\left(B_{1}=0.0045222, \mathrm{t}_{125}=8.725\right.$, $\mathrm{p}<0.0001, R^{2}=0.3862$; Figure 1, panel D).

For better approximation with a linear model we used a subset of the compiled data over the temperature range of $14-31^{\circ} \mathrm{C}$ resulting in 262 estimates for larval stages and 110 for hatch to emergence. This data subset restricted only the upper boundary of development rate estimates, above which a linear model is no longer a good approximation (Figure 1) [84]. The full GLMM model for development rates included fixed factors of temperature, photoperiod, diet, larval rearing density, and a dummy variable of temperature variability (constant or variable temperature). Estimates under constant temperatures came from laboratory studies. Estimates under variable temperatures came from both field studies in natural or seminatural conditions and laboratory studies with fluctuating temperature schemes accomplished using environmental chambers. Temperature fluctuations imposed in laboratory studies differed in magnitude, duration, and the life stage at which mosquitoes were exposed. To broadly assess the difference between constant and variable temperatures we created the dummy variable of temperature variability. Random factors included latitude and publication. Based on the minimum AIC and BIC, the best model for development rate from hatch to pupation included the fixed factor of temperature and the random factor of publication (Table 2). Similarly the best model for the development rate from hatch to emergence included only temperature as a fixed factor and the random factor of publication (Table 3).

For the second meta-analytic approach, inclusion required estimation of development rate for at least three temperatures in one experiment. The regression parameters for development rate on temperature are reported in supplementary tables (Additional file 1: Tables S3 and S4). The estimates of the developmental zero $(t)$ and degreeday model constant (K) are calculated and listed for each study for both hatch to emergence (Table 4) and hatch to pupation (Table 5). The literature search yielded 23 experiments meeting the criteria with the dependent variable development rate from hatch to emergence. The literature search yielded 20 experiments meeting the criteria for development rate from hatch to pupation. Results of experiments conflicted regarding the significance of the relationship between temperature and development rate. For example, considered separately, many of the studies did not show a significant, positive linear relationship between temperature and development rate (Tables 4 and 5). Of the 23 studies measuring hatch to emergence, 10 did not find a significant linear association. Similarly, 7 of 20 studies did not show a significant relationship for development rate from hatch to pupation and temperature. However,
Table 2 Linear mixed effects model selection of Ae. aegypti development rate from hatch to pupation

\begin{tabular}{llllll}
\hline Fixed factor & Random factor & AIC & $\boldsymbol{\Delta}$ AIC & BIC & $\boldsymbol{\Delta}$ BIC \\
\hline T, Ph, D, Dt, EV & Author, Lat & -36.74 & 436.16 & -15.53 & 443.07 \\
T, Ph, D, Dt, EV & Lat & -35.65 & 437.25 & -16.79 & 441.81 \\
T, Ph, D, Dt, EV & Author & -118.3 & 354.6 & -96.28 & 362.32 \\
T, Ph, D, Dt & Author & -124.9 & 348 & -105.6 & 353 \\
T, Ph, Dt, EV & Author & -127.4 & 345.5 & -108.2 & 350.4 \\
T, Ph, D, EV & Author & -196.5 & 276.4 & -175.2 & 283.4 \\
T, D, Dt, EV & Author & -215.4 & 257.5 & -193.9 & 264.7 \\
Ph, D, Dt, EV & Author & 39.35 & 512.25 & 58.62 & 517.22 \\
T, D, Dt & Author & -222.8 & 250.1 & -204.5 & 254.1 \\
T, Dt, EV & Author & -224 & 248.9 & -205.6 & 253 \\
T, D, EV & Author & -395.2 & 77.7 & -374.5 & 84.1 \\
D, Dt, EV & Author & 1.712 & 474.612 & 20.09 & 478.69 \\
T, D & Author & -403.5 & 69.4 & -386.2 & 72.4 \\
T, EV & Author & -466.8 & 6.1 & -448.9 & 9.7 \\
D, EV & Author & -96.4 & 376.5 & -79.1 & 379.5 \\
EV & Author & -131.6 & 341.3 & -117.3 & 341.3 \\
T & Author & $\mathbf{- 4 7 2 . 9}$ & $\mathbf{0}$ & $\mathbf{- 4 5 8 . 6}$ & $\mathbf{0}$ \\
\hline
\end{tabular}

Fixed factors considered were temperature $(\mathrm{T})$, photoperiod $(\mathrm{Ph})$, density in larvae/mL (D), diet in $\mathrm{mg} /$ larva/day (Dt), and environmental variability (EV). Environmental variability represents constant versus variable temperatures. Random factors included study author (Author) and latitude of origin for the Ae. aegypti study strain. AIC and BIC stand for Akaike and Bayes Information Criterion respectively. $\Delta$ represents the difference with respect to the minimum value. The best model with minimum values for each selection criterion is bolded. The AIC and BIC have negative values because the models had positive log-likelihoods, which occur because the probability densities evaluated at the observations are below 1 , which produces a negative logarithm. $\triangle \mathrm{AIC}$ and $\triangle B I C$ show differences with respect to the model that minimized each information criterion.

these data combined demonstrated an overall significantly positive association (Figure 2).

The linear association between development rate and temperature had significant heterogeneity for both hatch to pupation $\left(\mathrm{Q}_{\mathrm{T}}=242.4396, \mathrm{p}<0.0001\right)$ and hatch to emergence $\left(\mathrm{Q}_{T}=403.5, \mathrm{p}<0.0001\right)$. A linear mixed effects model was used to determine what other environmental factors might explain the heterogeneity in this relationship. Additional factors considered were initial larval rearing density, diet level (mg/larva/day), strain origin, latitude, and publication author. The model including only temperature as a fixed factor and the random factor of publication author best explained the heterogeneity in slope estimates for both the pupation group and emergence group. Once publication was included in the model, the test of residual heterogeneity was no longer significant for hatch to pupation $\left(\mathrm{Q}_{\mathrm{E}}=\right.$ 4.8582, $\mathrm{p}<0.3022)$ or hatch to emergence $\left(\mathrm{Q}_{E}=2.23\right.$, $\mathrm{p}<0.8971)$. Similarly, the developmental zero was significantly heterogeneous for both the hatch to pupation development rate $\left(\mathrm{Q}_{\mathrm{T}}=92.3908, \mathrm{p}<0.0001\right)$ and hatch 


\begin{tabular}{|c|c|c|c|c|c|}
\hline Fixed factor & Random factor & AIC & $\Delta \mathrm{AIC}$ & BIC & $\Delta \mathrm{BIC}$ \\
\hline T, Ph, D, Dt, EV & Author, Lat & -71.58 & 131.32 & -51.24 & 140.86 \\
\hline $\mathrm{T}, \mathrm{Ph}, \mathrm{D}, \mathrm{Dt}, \mathrm{EV}$ & Lat & -69.23 & 133.67 & -51.25 & 140.85 \\
\hline$T, P h, D, D t, E V$ & Author & -73.48 & 129.42 & -55.49 & 136.61 \\
\hline T, Ph, D, Dt & Author & -76.71 & 126.19 & -60.97 & 131.13 \\
\hline T, Ph, Dt, EV & Author & -78.76 & 124.14 & -63.02 & 129.08 \\
\hline T, Ph, D, EV & Author & -89.58 & 113.32 & -73.65 & 118.45 \\
\hline $\mathrm{T}, \mathrm{D}, \mathrm{Dt}, \mathrm{EV}$ & Author & -98.46 & 104.44 & -82.06 & 110.04 \\
\hline $\mathrm{Ph}, \mathrm{D}, \mathrm{Dt}, \mathrm{EV}$ & Author & 24.1 & 227 & 39.84 & 231.94 \\
\hline $\mathrm{T}, \mathrm{D}, \mathrm{Dt}$ & Author & -105.3 & 97.6 & -91.2 & 100.9 \\
\hline T, Dt, EV & Author & -106.5 & 96.4 & -92.4 & 99.7 \\
\hline $\mathrm{T}, \mathrm{D}$, EV & Author & -140.2 & 62.7 & -125 & 67.1 \\
\hline D, Dt, EV & Author & 9.06 & 211.96 & 23.13 & 215.23 \\
\hline $\mathrm{T}, \mathrm{D}$ & Author & -147 & 55.9 & -134.3 & 57.8 \\
\hline T, EV & Author & -195 & 7.9 & -181.5 & 10.6 \\
\hline$D, E V$ & Author & -12.11 & 190.79 & 0.55 & 192.65 \\
\hline EV & Author & -43.19 & 159.71 & -32.39 & 159.71 \\
\hline $\mathbf{T}$ & Author & -202.9 & 0 & -192.1 & 0 \\
\hline
\end{tabular}

Fixed factors considered were temperature $(\mathrm{T})$, photoperiod $(\mathrm{Ph})$, density in larvae/mL (D), diet in $\mathrm{mg} /$ larva/day (Dt), and environmental variability (EV). Environmental variability represents constant versus variable temperatures. Random factors included study author (Author) and latitude of origin for the $A e$. aegypti study strain. The best model with minimum values for each selection criterion is bolded.

to emergence $\left(\mathrm{Q}_{\mathrm{T}}=675.6708, \mathrm{p}<0.0001\right)$. Once temperature had been considered, the residual heterogeneity in the developmental zero was explained by publication author such that the test for residual heterogeneity was no longer significant (hatch to pupation: $\mathrm{Q}_{\mathrm{E}}=2.2802$, $\mathrm{p}<0.6844$; hatch to emergence: $\left.\mathrm{Q}_{\mathrm{E}}=1.0234, \mathrm{p}<0.9847\right)$.

Asymmetry was apparent when plotting effect measures against study size in funnel plots (Figure 3). In the absence of systematic heterogeneity, points should fall within the range indicated by the inverted cone in funnel plots. Asymmetry may be a result of publication bias or systematic heterogeneity. With the inclusion of publication author as a random effect in the model, the asymmetry was no longer evident and the funnel plots no longer indicated heterogeneity for hatch to emergence or hatch to pupation (Additional file 2: Figure S1 and Additional file 3: Figure S2).

The range of diets considered across all studies was $0.01 \mathrm{mg} /$ larva/day to $435.2 \mathrm{mg} /$ larva/day. However, $96.6 \%$ of studies used values within the range of $0.01 \mathrm{mg} / \mathrm{larva} /$ day to $6.8 \mathrm{mg} / \mathrm{larva} /$ day. Comparisons of diet level with development rate are shown in Figure 4, panels $\mathrm{A}$ and $\mathrm{C}$. The larval rearing density considered across the studies ranged from 0.01 larvae/mL to 8 larvae $/ \mathrm{mL}$, and comparisons with development rate are shown in Figure 4, panels B and D. Approximately $69 \%$ of larval rearing density levels used by studies in the meta-analysis fell between 0.1 larva/mL and 1 larva/mL.

\section{Discussion}

We hypothesized, first, that development rate is significantly influenced by several environmental factors and that the interaction of these factors is an important predictor of development rate variation. The results of both meta-analytic approaches suggest that temperature is the main fixed factor driving development rate, to the exclusion of other factors of known importance such as diet and density. This bolsters the contention that temperature is the most important ecological determinant and, when modeling development, sufficient to predict development rate [111]. When larvae experience nutritional deprivation or high densities, this can dampen [112] or exacerbate [36] the impacts of temperature. Thus, while research suggests that diet [73,113] and larval rearing density [84,114] do matter, these results underscore that they should not be considered to the exclusion of temperature. Based on model selection, the relative importance of these factors can be ranked as temperature followed by temperature variability, larval rearing density, then diet, and lastly photoperiod (Table 2, Table 3). The relative importance of factors is consistent between the periods of hatch to pupation and hatch to emergence. While this analysis shows other variables such as latitude were not significant in explaining development rate variation, they may impact other important life history traits including survival, body size, fecundity [33], and morphology [115].

The relationship between temperature and development rate is linear within a median temperature range [116-119], and features of this linear relationship, such as slope and intercept, have biological interpretations. The slope of this relationship is considered the cumulative effect of temperature on the rate of development, and the intercept can be interpreted as the theoretical temperature at which development can no longer occur [5,109], also called the developmental zero. Although at extremes of low temperature the development curve is non-linear, the linear portion is extrapolated to the intersection with the temperature axis to estimate the developmental zero [120]. This extrapolation based on slope may, in part, explain the large variation in the estimates reported in Tables 4 and 5 . This may also explain estimates that were less than zero, which is biologically implausible. Meta-analysis these parameters across many studies allows for outliers to be more easily identified.

Despite these limitations, the developmental zero is often considered a fixed characteristic of a species for the purposes of modeling and predicting population abundance 
Table 4 Studies that estimated development rate to adult emergence over three or more temperatures

\begin{tabular}{|c|c|c|c|c|c|c|c|c|}
\hline Study & Latitude & Sex & $\mathrm{t}\left({ }^{\circ} \mathrm{C}\right)$ & $\mathrm{K}$ & $\mathrm{n}$ & $r^{2}$ & $p$-value & \\
\hline Bar-Zeev 1958 [102] & 31.0461 & $\mathrm{~F}$ & 12.83 & 121.86 & 100 & 0.9959 & $6.21 \mathrm{E}-06$ & $* * *$ \\
\hline Beserra et al. 2006 [66] & -7.4908 & C & 13.35 & 186.74 & 120 & 0.9874 & 0.00634 & * \\
\hline Beserra et al. 2006 [66] & -6.38 & C & 9.40 & 280.23 & 120 & 0.9962 & 0.03915 & * \\
\hline Beserra et al. 2006 [66] & -7.2256 & C & 8.42 & 243.21 & 120 & 0.8418 & 0.2604 & \\
\hline Beserra et al. 2006 [66] & -7.3 & C & 13.63 & 173.32 & 120 & 0.9949 & 0.002563 & $* *$ \\
\hline Beserra et al. 2006 [66] & -6.9669 & C & 18.35 & 102.82 & 120 & 0.9644 & 0.1209 & \\
\hline Farjana et al. 2012 [34] & -3.3439 & $\mathrm{~F}$ & 9.95 & 257.90 & 100 & 0.981 & 0.08805 & \\
\hline Farjana et al. 2012 [34] & -3.3439 & $\mathrm{~F}$ & 11.44 & 158.13 & 100 & 0.9403 & 0.1572 & \\
\hline Farjana et al. 2012 [34] & -3.3439 & M & 9.95 & 209.14 & 100 & 0.9882 & 0.06917 & \\
\hline Farjana et al. 2012 [34] & -3.3439 & M & 11.69 & 137.59 & 100 & 0.9318 & 0.1682 & \\
\hline Headlee 1941 [104] & 40.486217 & C & 10.21 & 187.68 & 200 & 0.9828 & 0.0838 & \\
\hline Headlee 1940 [103] & 40.486217 & C & 8.38 & 219.88 & 200 & 0.9858 & 0.0007197 & $* * *$ \\
\hline Kamimura et al. 2002 [70] & 24.8934 & $\mathrm{~F}$ & 9.93 & 162.44 & 50 & 0.9902 & 0.06328 & \\
\hline Kamimura et al. 2002 [70] & -7.2653 & $\mathrm{~F}$ & 10.68 & 151.77 & 50 & 0.9985 & 0.02504 & $*$ \\
\hline Kamimura et al. 2002 [70] & -9.2628 & $\mathrm{~F}$ & 11.38 & 144.78 & 50 & 0.9472 & 0.1476 & \\
\hline Kamimura et al. 2002 [70] & 24.8934 & M & 8.19 & 176.84 & 50 & 0.9931 & 0.05285 & * \\
\hline Kamimura et al. 2002 [70] & -7.2653 & M & 10.10 & 148.90 & 50 & 0.9977 & 0.03039 & * \\
\hline Kamimura et al. 2002 [70] & -9.2628 & M & 9.09 & 163.45 & 50 & 0.9142 & 0.1893 & \\
\hline Lachmajer \& Hien 1975 [86] & 14.0583 & C & 6.85 & 141.43 & 6300 & 0.9958 & 0.04125 & * \\
\hline Ofuji 1963 [100] & 32.2 & $\mathrm{~F}$ & 10.76 & 133.80 & 20 & 0.96 & 0.00344 & $* *$ \\
\hline Ofuji 1963 [100] & 32.2 & M & 10.45 & 129.82 & 20 & 0.9514 & 0.004608 & $* *$ \\
\hline Rueda et al. 1990 [78] & 35.7721 & C & 11.17 & 129.35 & 20 & 0.8669 & 0.006966 & $*$ \\
\hline Tun-Lin et al. 2000 [73] & -10.58 & C & 46.31 & 332.82 & 200 & 0.8497 & 0.02594 & $*$ \\
\hline
\end{tabular}

Developmental zero $(\mathrm{t})$ and linearized degree day model constant $(\mathrm{K})$ are listed along with the correlation coefficient and $\mathrm{p}$-value of the linear regression between temperature and development rate. Level of significance is indicated by the number of asterisks $\left({ }^{*}<0.01 ;{ }^{* *}<0.001 ;{ }^{* * *}<0.0001\right)$. Sex is listed as $C$ if values represent a combination of males and females.

$[39,109,121,122]$. Thus, we also sought to test the hypothesis that the effect of temperature and the developmental zero are fixed characteristics of Ae. aegypti strains. While the meta-analytic results are consistent with a positive, linear relationship between temperature and development rate, tests for heterogeneity suggest a significant amount of variation in response to temperatures within this range. These data do not support the hypothesis that the developmental zero and the effect of temperature are fixed constants. Both the effect of temperature and the developmental zero are heterogeneous across studies considered in the meta-analysis. These results have implications for the modeling of development rate as well as population abundance, which often relies on development times of larval populations $[22,123]$. These compiled data may be used as the basis for modeling these parameters as a distribution rather than choosing one value from a single study. Variation in development time (i.e. the inverse of development rate) has been modeled as a continuous random variable with a distribution of frequencies, such as the normal distribution [124] or with a heterogeneity factor [125]. Other modeling approaches to incorporate development rate variation stochastically by treating development rate as a random variable dependent on the variability in the level of catalytic enzymes [126-128], positing a biophysical basis for variability.

There are several hypotheses to address why the response to temperature may be heterogeneous. Our results indicate that factors of larval rearing density, diet, latitude, and photoperiod were not factors that could explain heterogeneity of the effect of temperature. A limitation of this analysis was the narrow range of reported values of diet and initial larval rearing density. While many studies reported at least one level of different factors such as temperature, diet, and larval rearing density, few studies in Ae. aegypti examined development across gradients of multiple environmental conditions. Such experiments are needed in order to establish the relative importance of environmental factors in the variation of development rates. Assessing the impact of varied environmental conditions on the developmental phenotypes of mosquito larvae can be complex with interactive effects $[18,24,129]$. For example, Padhmanhaba et al. 2011 [36] show that increased the rearing temperature for starved Ae. aegypti 
Table 5 Studies that estimated development rate to pupation over three or more temperatures

\begin{tabular}{|c|c|c|c|c|c|c|c|}
\hline Study & Latitude & $\mathrm{t}\left({ }^{\circ} \mathrm{C}\right)$ & K & n & $r$ & p-value & \\
\hline Bar-Zeev 1958 [102] & 31.0461 & -14.21 & 86.22 & 100 & 0.9975 & 0.001269 & $* *$ \\
\hline Becnel \& Undeen 1992 [77] & 15.87 & 1.13 & 185.46 & 250 & 0.883 & 0.2222 & \\
\hline Beserra et al. 2006 [66] & -7.4908 & -9.91 & 148.46 & 120 & 0.8963 & 0.01464 & * \\
\hline Beserra et al. 2006 [66] & -6.38 & -7.75 & 187.97 & 120 & 0.9758 & 0.001609 & $* *$ \\
\hline Beserra et al. 2006 [66] & -7.2256 & -9.41 & 130.57 & 120 & 0.8663 & 0.02164 & * \\
\hline Beserra et al. 2006 [66] & -7.3 & -4.37 & 200.88 & 120 & 0.4404 & 0.222 & \\
\hline Beserra et al. 2006 [66] & -6.9669 & -12.56 & 114.48 & 120 & 0.8652 & 0.02193 & * \\
\hline Gilpin \& McClelland 1979 [84] & -10.9491 & -10.81 & 82.27 & 300 & 0.8875 & 4.80E-07 & $* * *$ \\
\hline Kamimura et al. 2002 [70] & 24.8934 & -1.62 & 28.64 & 50 & 0.9634 & 0.1225 & \\
\hline Kamimura et al. 2002 [70] & -7.2653 & -9.70 & 122.78 & 50 & 0.9995 & 0.01357 & * \\
\hline Kamimura et al. 2002 [70] & -9.2628 & -9.89 & 122.34 & 50 & 0.9035 & 0.2011 & \\
\hline Keirans \& Fay 1968 [97] & 18.2208 & -10.79 & 102.18 & 50 & 0.9729 & $6.26 \mathrm{E}-06$ & $* * *$ \\
\hline Lachmajer \& Hien 1975 [86] & 14.0583 & -10.00 & 112.68 & 6300 & 0.9598 & 0.1286 & \\
\hline Mohammed \& Chadee 2011 [59] & 10.6389 & 69.92 & 365.94 & 600 & 0.002094 & 0.9069 & \\
\hline Ofuji 1963 [100] & 32.2 & -9.70 & 105.79 & 20 & 0.9095 & 0.01189 & * \\
\hline Padmanabha et al. 2011 [36] & 10.9861 & -9.09 & 100.97 & 160 & 0.9644 & 0.0004806 & $* * *$ \\
\hline Rueda et al. 1990 [78] & 35.7721 & -10.65 & 101.43 & 20 & 0.7966 & 0.01671 & * \\
\hline Thu et al. 1998 [76] & 21.914 & 76.45 & 1124.99 & 100 & 0.0356 & 0.8113 & \\
\hline Tsuda \& Takagi 2001 [72] & 19.5177 & -10.40 & 153.68 & 50 & 0.6096 & 0.03826 & * \\
\hline Tun-Lin et al. 2000 [73] & -10.58 & -36.15 & 727.80 & 200 & 0.887 & 0.01671 & * \\
\hline
\end{tabular}

Developmental zero $(\mathrm{t})$ and linearized degree day model constant $(\mathrm{K})$ are listed along with the correlation coefficient and $\mathrm{p}$-value of the linear regression between temperature and development rate. Level of significance is indicated by the number of asterisks $\left({ }^{*}<0.01 ;{ }^{* *}<0.001 ;{ }^{* * *}<0.0001\right)$.

larvae impacts development rate, and this impact changes depending on the larval stage and the temperature.

Publication author was adequate to explain heterogeneity in the effect of temperature on development rates. It is difficult to identify the aspects of this factor to describe its significance in explaining development rate variation. We evaluated the dichotomy of laboratory versus field experiments, which generally corresponded to constant versus variable temperatures. Mosquito response to variable rather than constant temperatures has been a recent focus both for life history traits and vectorial capacity [123,130-134]. Variable temperatures have been shown to increase [135], decrease [118], and have no impact [136] on development rates of mosquitoes and other insects. Inconsistency in the relationship between temperature and development rate has been attributed to field conditions versus laboratory conditions [36]. To test this, we compared development rates estimated under constant versus variable temperature conditions, which corresponded to laboratory versus field conditions. This comparison showed no significant difference overall in the relationship between development rate and temperature based on temperature variability for either larval stages or to hatch to emergence (Figure 2). This finding is consistent with recent reports that Ae. aegypti life-history traits depend not only on variability but also the magnitude of temperature fluctuations [134].

The factor of publication may be a proxy for methodological differences such as diet composition (i.e. ingredients of diet). Of the 49 studies, almost all reported information on diet composition. However, few used the same diet preparations, and this prevented this factor from being included in meta-analysis. Some diets were created from detritus of the larval habitat in order to mimic natural conditions [36,61,137] or incorporated detritus [62]. The majority however provided no explanation for the choice of diets. Diet choice can influence development rate as well as interspecific larval competition [138,139] and adult wing length [60]. To facilitate comparison of larval performance across populations, these findings support a need for standardization of diet composition for laboratory colonies. This is especially important in the context of transgenics. Our literature search yielded only two studies with estimating development rate of Ae. aegypti transgenic strains. The low sample size impeded statistical comparison of transgenic versus wild-type development rate estimates, leading to singularity errors in the linear mixed effects modeling. Future comparisons of transgenic and wild strains in other important life-history traits such as body size, fecundity, and longevity may also be informative. Estimating and evaluating life- 


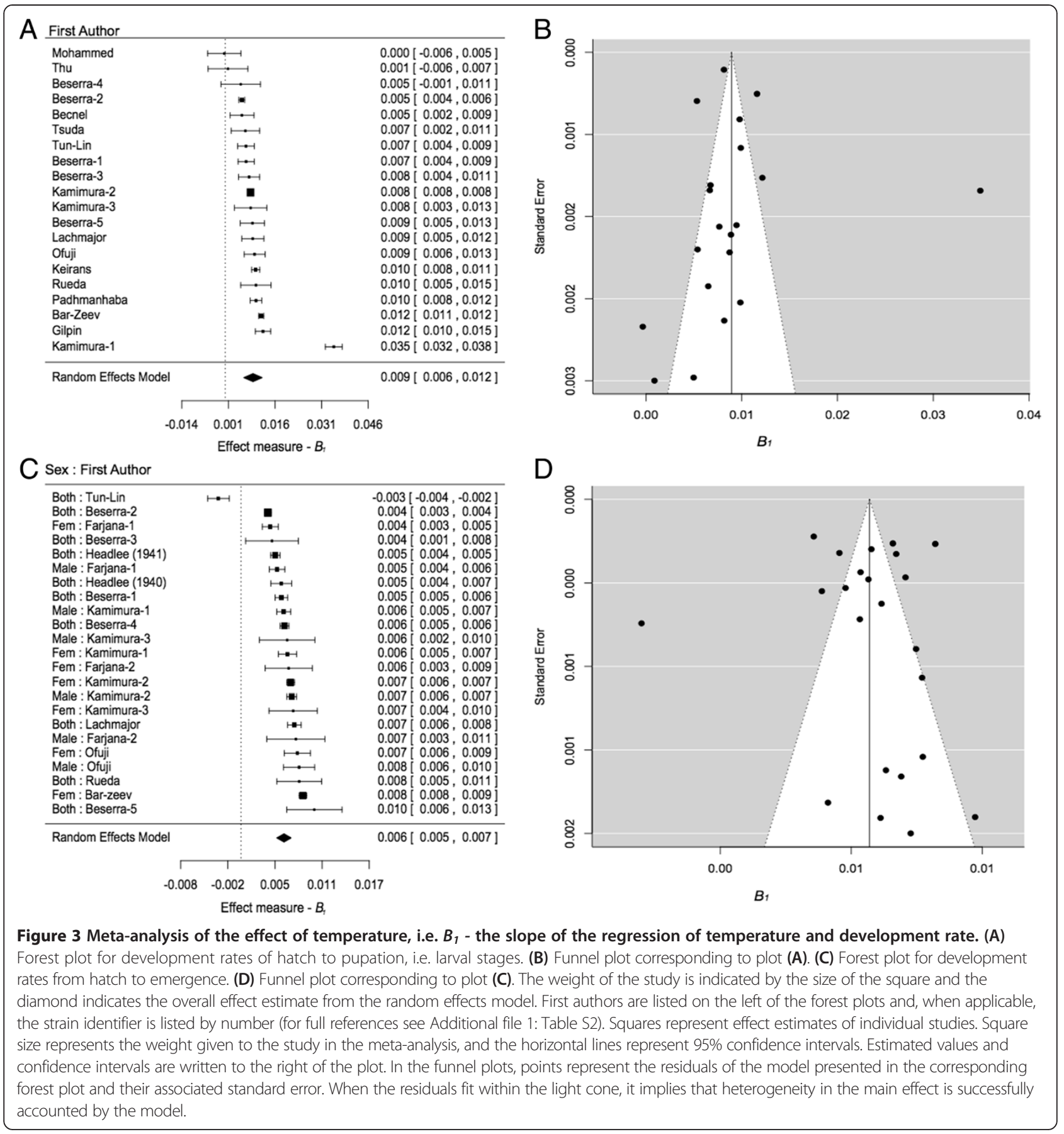

history traits across different environmental conditions is critical to provide a basis for comparison between wild and transgenic strains and may guide future transgenic release programs $[29,58,69]$.

Other factors not considered in this analysis may also impact the effect of temperature, and perhaps contribute to heterogeneity. Examples include genetic variation, microbial symbiotic partners, and maternal effects. Population differences in larval survival and body size in response to different temperatures have been demonstrated in other insects [140] but such differences have also been attributed to adaptive phenotypic plasticity through a hormonal cascade that stops growth [141]. Inclusion of latitude as a variable was one proxy for comparing populations broadly. Latitude has been suggested as a potential gradient for local adaptation to thermal stress in mosquitoes [142]. However, our results suggest latitude does not explain heterogeneity of the effect of temperature. The strain origin/ 

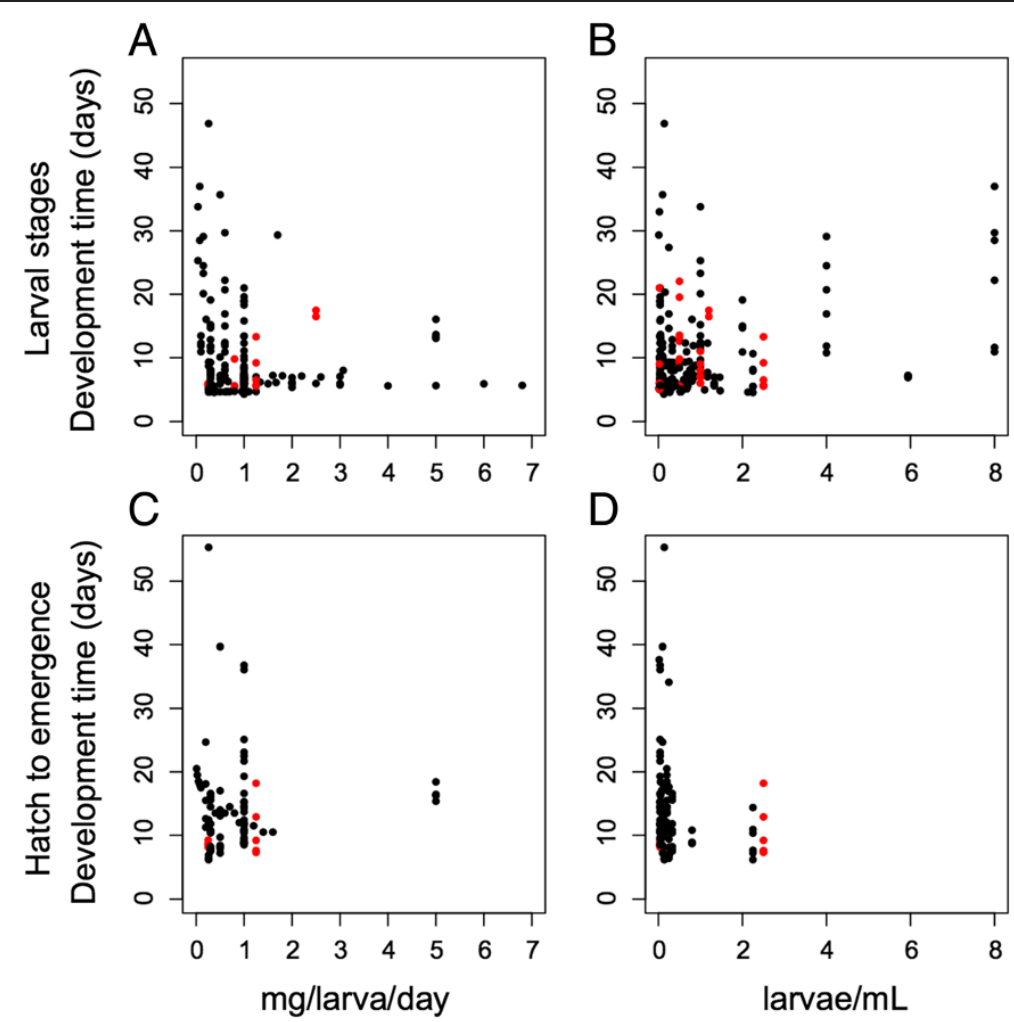

Figure 4 Development time of hatch to pupation, i.e. larval stages, compared to diet (A) and density (B), and development time from hatch to emergence compared to diet (C) and density (D). Character color indicates laboratory (black) and field studies (red).

study location was included as a random effect as another indirect proxy for genetic differences in population, but we found no associations with strain origin. There is evidence of genetic structure across geographic space [143] and seasons [144], but examples of strong local adaptation in development rate is lacking in Ae. aegypti populations [123]. Richardson et al. [123] suggested that the lack of strong local adaptation may be evidence of a limited capacity to evolve in response to thermal stress. More studies are needed to evaluate the potential for adaptive phenotypic plasticity in response to temperature in Ae. aegpyti that could explain the heterogeneity of responses characterized here. Further, in natural conditions other ecological factors not considered here such as interspecific competition, such as between Ae. aegypti and Ae. albopictus [34,137], and predation [117] may impact development rate and warrant further investigation.

Recent work compares life-history traits such as body size and fecundity across multiple environmental conditions $[145,146]$. More empirical estimates of these traits across environments have been recently made available since the preparation of this work $[123,134,147,148]$, a limitation of conducting a meta-analysis in a rapidly developing field of research. Recent advances suggest variation in these traits has been attributed to responses to environmental conditions during development
$[20,130,149]$ as well as adaptive genetic responses due to selection at different temperatures $[7,150]$. Developmental life-history traits are of particular epidemiological importance for arboviral disease dynamics as they have been associated with critical aspects of vectorial capacity such as changes in bite rate, dispersal [151] and virus infection and dissemination [152].

\section{Conclusion}

Beyond utility for vector population control, development rate estimates may be useful for modeling and understanding disease transmission. There is evidence that larval environment impacts adult dispersion of Ae. aegpyti [153] as well as arbovirus infection [154]. Depinay et al. 2004 [155] have demonstrated improved predictive power for malaria transmission dynamics when using vector population parameters including lifehistory traits of anopheline mosquitoes. Meta-analysis confirms that temperature is the most important ecological determinant of development rate in Ae. aegypti but that the effect is heterogeneous. Ignoring the heterogeneity in response to temperature may be problematic for using development rate estimates to model vector populations and predicting the impact of temperature on vector-borne disease transmission. 


\section{Additional files}

Additional file 1: Table S1. Online database searched in December 2011 for research papers pertaining to Aedes aegypti development rate estimates under various environmental conditions including temperature, diet and intraspecific rearing density. Databases are ordered based on specificity to mosquito literature from broad to specific. Table S2. Full bibliography for the 65 studies included in the factors influencing development rate and survival of Aedes aegypti. Table S3. Linear regression parameter estimates for studies that experimentally examined the relationship between development rate and temperature for the stages from first instar to adult emergence. Table S4. Linear regression parameter estimates for studies that experimentally examined the relationship between the development rate and temperature for the life stages from hatch to pupation.

Additional file 2: Figure S1. Meta-analysis of the effect of temperature, i.e. $B_{1}$ - the slope of the regression of temperature and development rate from hatch to emergence. (A) Forest plot of best model with random effect of publication author. (B) Funnel plot corresponding to plot (A). The weight of the study is indicated by the size of the square and the diamond indicates the overall effect estimate from the random effects model. Squares represent effect estimates of individual studies. Square size represents the weight given to the study in the meta-analysis, and the horizontal lines represent 95\% confidence intervals. Estimated values and confidence intervals are written to the right of the plot. In the funnel plots, dots represent the residuals of the publication authors corresponding with the best model and their associated standard error. When the residuals fit within the light cone, it implies that heterogeneity in the main effect is successfully accounted for by the model.

Additional file 3: Figure S2. Meta-analysis of the effect of temperature, i.e. $B_{1}$ - the slope of the regression of temperature and development rate from hatch to pupation. (A) Forest plot of best model with random effect of publication author. (B) Funnel plot corresponding to plot (A). See Figure S1 caption.

\section{Competing interests}

All authors have read and understood the BMC Ecology policy on declaration of competing interests and declare: no financial relationships with any organizations that might have an interest in the submitted work; no other relationships or activities that could appear to have influenced the submitted work; no patents relating to the content of the manuscript; no financial or non-financial competing interests.

\section{Authors' contributions}

JC conceived the study, acquired data through a literature search, analyzed and interpreted data, and drafted manuscript. MQB acquired data through literature search, interpreted data, and revised manuscript critically for important intellectual content. Both authors have read and approved the final manuscript.

\section{Acknowledgements}

Thank you to B. Reiskind for providing original data from Reiskind \& Lounibus 2009. Thank you to N. Gerardo for providing valuable feedback and edits, and to J. Garcia, L. Hyunh, B. Parker, T. De Man for comments which improved the quality of this manuscript. JC received stipend support by the National Institutes of Health (NIH) Training Grant in Population Biology of Infectious Disease during the completion of this research. MQB's participation in this research was supported by a Marie Curie International Incoming Fellowship within the 7th European Community Framework Programme.

\section{Author details}

'Department of Biology, Emory University, 1510 Clifton Road NE, Atlanta, GA 30322, USA. Dipartimento di Medicina Sperimentale e Scienze Biochimiche, Sezione di Microbiologia, Edificio B, 3 Piano, Via Gambuli, 06132 Perugia, Italy.

Received: 6 September 2013 Accepted: 24 January 2014

Published: 5 February 2014

\section{References}

1. Golizadeh A, Zalucki M: Estimating temperature-dependent developmental rates of potato tuberworm, Phthorimaea operculella (Lepidoptera: Gelechiidae). Insect Sci 2012, 19:609-620.

2. Vitolo HF, Souza GM, Silveira JAG: Cross-scale multivariate analysis of physiological responses to high temperature in two tropical crops with C-3 and C-4 metabolism. Environ Exp Bot 2012, 80:54-62.

3. Baras E, Ginanjar R, Ahmad M, Permana A, Priyadi A, Legendre M, Pouyard L, Slembrouck J: Biology and culture of the clown loach Chromobotia macracanthus. Aquat Living Resour 2012, 25:121-142.

4. Gillooly J: Effects of size and temperature on metabolic rate. Science 2001, 293:2248-2251.

5. Ahlgren G: Temperature fluctuations in bioloy and their application to algal growth constants. Oikos 1987, 49:177-190.

6. Davidson J: On the relationship between temperature and rate of development of insects at constant temperatures. J Anim Ecol 1944, 13:26-38.

7. Dixon AFG, Honek A, Keil P, Kotela MAA, Sizling AL, Jarosik V: Relationship between the minimum and maximum temperature thresholds for development in insects. Funct Ecol 2009, 23:257-264.

8. Laudien $\mathrm{H}$ : Changing reaction systems. In Temperature and life. Edited by Precht H, Christopherson J, Hensel H, Larcher W. New York: Springer-Verlag; 1973:355-399.

9. Wigglesworth VB: The principles of insect physiology. London: Chapman and Hall; 1972.

10. Watt K: Ecology and resource management, a quantitative approach. New York: McGraw Hill; 1968.

11. Messenger P: Bioclimatic studies with insects. Annu Rev Entomol 1959, 4:183-206.

12. Andrewartha HG, Birch LC: The distribution and abundance of animals. Chicago: University of Chicago Press; 1954.

13. Powsner $L$ : The effects of temperature on the durations of the developmental stages of Drosophila melanogaster. Physiol Zool 1935, 8:474-520.

14. Janisch $E$ : The influence of temperature on the life-history of Insects. T Entomo/ Soc Lon 1932, 80:137-168.

15. Urarov BP: Insects and climate. T Entomol Soc Lon 1931, 79:1-238.

16. Cook W: Some effects of alternating temperaures on the growth and metabolism of cutworm larvae. J Econ Entomol 1927, 20:769-782.

17. Yoshioka M, Couret J, Kim F, McMillan J, Burkot TR, Dotson EM, Kitron U, Vazquez-Prokopec GM: Diet and density dependent competition affect larval performance and oviposition site selection in the mosquito species Aedes albopictus (Diptera: Culicidae). Parasite Vector 2012, 5:225.

18. Kingsolver J, Huey R: Size, temperature, and fitness: three rules. Evol Ecol Res 2008, 10:251-268.

19. Evans LM, Clark JS, Whipple AV, Whitham TG: The relative influences of host plant genotype and yearly abiotic variability in determining herbivore abundance. Oecologia 2012, 168:483-489.

20. Gillooly JF, Charnov EL, West GB, Savage VM, Brown JH: Effects of size and temperature on developmental time. Nature 2002, 417:70-73.

21. Weaver SC, Reisen WK: Present and future arboviral threats. Antivir Res 2010, 85:328-345.

22. Juliano SA: Species interactions among larval mosquitoes: context dependence across habitat gradients. Annu Rev Entomol 2009, 54:37-56.

23. Richards SL, Lord CC, Pesko KN, Tabachnick WJ: Environmental and biological factors influencing Culex pipiens quinquefasciatus (Diptera: Culicidae) vector competence for West Nile virus. Am J Trop Med Hyg 2010, 83:126-134.

24. Gilles J, Lees R, Soliban S, Benedict M: Density-dependent effects in experimental larval populations of Anopheles arabiensis (Diptera: Culicidae) can be negative, neutral, or overcompensatory depending on density and diet levels. J Med Entomol 2011, 48:296-304.

25. Vazquez-Prokopec GM: Dengue control: the challenge ahead. Future Microbiol 2011, 6:251-253.

26. Ghosh D, Manson SM, McMaster RB: Delineating West Nile virus transmission cycles at various scales: the nearest neighbor distance-time model. Cartogr Geogr Inform 2010, 37:149-163.

27. Bisset JA, Marin R, Rodriguez MM, French L, Diaz M, Perez O: Insecticide resistance in two Aedes aegypti (Diptera: Culicidae) strains from Costa Rica. J Med Entomol 2013, 50:352-361. 
28. McAllister JC, Godsey MS, Scott ML: Pyrethroid resistance in Aedes aegypti and Aedes albopictus from Port-au-Prince, Haiti. J Vec Ecol 2012, 37:325-332.

29. Legros M, Xu C, Okamoto K, Scott TW, Morrison AC, Lloyd AL, Gould F: Assessing the feasibility of controlling Aedes aegypti with transgenic methods: a model-based evaluation. PLOS ONE 2012, 7:e52235.

30. IPCC: Summary for Policymakers. In Climate Change 2007: The Physical Science Basis. Contribution of Working Group I to the Fourth Assessment Report of the Intergovernmental Panel on Climate Change. Edited by Solomon S, Qin D, Manning M, Chen Z, Marquis M, Averyt KB, Tignor M, Miller HL. Cambridge, United Kingdom and New York, NY, USA: Cambridge University Press; 2007.

31. Parkash R, Ramniwas S, Kajla B: Climate warming mediates range shift of two diffetentially adapted. J Asia-Pac Entomol 2013, 16:147-153.

32. Folguera G, Bastias DA, Bozinovic F: Impact of experimental thermal amplitude on ectotherm performance: adaptation to climate change variability? Comp Biochem Phys A 2009, 154:389-393.

33. Kollberg I, Bylund H, Schmidt A, Gershenzon J, BjÖrkman C: Multiple effects of temperature, photoperiod and food quality on the performance of a pine sawfly. Ecol Entomol 2013, 38:201-208.

34. Farjana T, Tuno N, Higa Y: Effects of temperature and diet on development and interspecies competition in Aedes aegypti and Aedes albopictus. Med Vet Entomol 2012, 26:210-217.

35. Dell Al, Pawar S, Savage VM: Systematic variation in the temperature dependence of physiological and ecological traits. PNAS 2011, 108:10591-10596.

36. Padmanabha H, LORD CC, LOUNIBOS LP: Temperature induces trade-offs between development and starvation resistance in Aedes aegypti (L.) larvae. Med Vet Entomol 2011, 25:445-453

37. Chown S, Gaston K: Body size variation in insects: a macroecological perspective. Biol Rev 2010, 85:139-169.

38. Flenner I, Richter $\mathrm{O}$, Suhling F: Rising temperature and development in dragonfly populations at different latitudes. Freshwater Biol 2010, 55:397-410.

39. de Jong G: A biophysical interpretation of temperature-dependent body size in Drosophila aldrichi and D. buzzatii. J Therm Biol 2010, 35:85-99.

40. Yang LH, Rudolf VHW: Phenology, ontogeny and the effects of climate change on the timing of species interactions. Ecol Lett 2010, 13:1-10

41. Farnesi LC, Martins AJ, Valle D, Rezende GL: Embryonic development of Aedes aegypti (Diptera: Culicidae): influence of different constant temperatures. Mem Inst Oswaldo Cruz 2009, 104:124-126.

42. Stav G, Blaustein L, Margalit Y: Individual and interactive effects of a predator and controphic species on mosquito populations. Ecol Appl 2005, 15:587-598.

43. Agnew $P$, Hide $M$, Sidobre $C$, Michalakis $Y$ : A minimalist approach to the effects of density-dependent competition on insect life-history traits. Ecol Entomol 2002, 27:396-402.

44. Blanford S, Jenkins NE, Read AF, Thomas MB: Evaluating the lethal and pre-lethal effects of a range of fungi against adult Anopheles stephensi mosquitoes. Malar J 2012, 11:365.

45. Chaves L, Keogh C, Vazquez-Prokopec G, Kitron U: Combined sewage overflow enhances oviposition of Culex quinquefasciatus (Diptera: Culicidae) in urban areas. J Med Entomol 2009, 46:220-226.

46. Walker ED, Merritt RW, Kaufman MG, Ayres MP, Riedel MH: Effects of variation in quality of leaf detritus on growth of the eastern tree-hole mosquito, Aedes triseriatus (Diptera: Culicidae). Can J Zool 1997, 75:706-718

47. Beck S: Insect thermoperiodism. Annu Rev Entomol 1983, 28:91-108.

48. Arnqvist $\mathrm{G}$, Johansson F: Ontogenetic reaction norms of predator-induced defensive morphology in dragonfly larvae. Ecology 1998, 79:1847-1858.

49. Knies J, Kingsolver J: Erroneous Arrhenius: modified Arrhenius model best explains the temperature dependence of ectotherm fitness. Am Nat 2010, 176:227-233.

50. Schwander T, Leimar O: Genes as leaders and followers in evolution. TREE 2011, 26:143-151.

51. Weaver SC, Reisen WK: Present and future arboviral threats. Antivir Res 2009. doi:10.1016/j.antiviral.2009.10.008.

52. Pesko K, Westbrook C, Mores C, Lounibos L, Reiskind M: Effects of infectious virus dose and bloodmeal delivery method on susceptibility of Aedes aegypti and Aedes albopictus to Chikungunya virus. J Med Entomol 2009, 46:395-399.
53. MacClelland GAH: A worldwide survey of variation in scale pattern of the abdominal tergum of Aedes aegypti (L.) (Diptera: Culicidae). T Roy Ent Soc London 1974, 126:239-259.

54. Tabachnick W, Powell JR: A world-wide survey of genetic variation in the yellow fever mosquito, Aedes aegypti. Gen Res 1979, 34:215-229

55. Failloux A-B, Vazeille M, Rodhain F: Geographic genetic variation in populations of the dengue virus vector Aedes aegypti. Mol Evol 2002, 55:653-663.

56. Mousson L, Dauga C, Garrigues T, Schaffner F, Vazeille M, Failloux A-B: Phylogeography of Aedes (Stegomyia) aegypti (L.) and Aedes (Stegomyia) albopictus (Skuse) (Diptera: Culicidae) based on mitochondrial DNA variations. Gen Res 2005, 86:1-11.

57. Gurevitch J, Curtis P, Jones M: Meta-analysis in ecology. Adv Ecol Res 2001 32:199-207.

58. Bargielowski I, Nimmo D, Alphey L, Koella JC: Comparison of life history characteristics of the genetically modified OX513A line and a wild type strain of Aedes aegypti. PLOS ONE 2011, 6:e20699.

59. Mohammed A, Chadee D: Effects of different temperature regimens on the development of Aedes aegypti (L.) (Diptera: Culicidae) mosquitoes. Acta Trop 2011, 119:38-43.

60. Padmanabha H, Bolker B, LORD CC, Rubio C, LOUNIBOS LP: Food availability alters the effects of larval temperature on Aedes aegypti growth. J Med Entomol 2011, 48:974-984.

61. Maciá A: Effects of larval crowding on development time, survival and weight at metamorphosis in Aedes aegypti (Diptera: Culicidae). Rev Soc Entomol Argent 2009, 68:107-114.

62. Reiskind $M$, Lounibus $L$ : Effects of intraspecific larval competition on adult longevity in the mosquitoes Aedes aegypti and Aedes albopictus. Med Vet Entomol 2009, 23:62-68.

63. Tejerina E, Almeida F, Almiron W: Bionomics of Aedes aegypti subpopulations (Diptera: Culicidae) from Misiones Province, northeastern Argentina. Acta Trop 2009, 109:45-49.

64. Beserra E, Castro F: Biologia Comparada populações de Aedes (Stegomyia) aegypti (L.)(Diptera: Culicidae) da Paraíba; Compared biology of populations of Aedes (Stegomyia) aegypti (L.)(Diptera: Culicidae de Paraiba. Neotrop Entomol 2008, 37:081-085.

65. Chang $H$, Hsu E, Teng H, Ho C: Differential Survival of Aedes aegypti and Aedes albopictus (Diptera: Culicidae) larvae exposed to low temperatures in Taiwan. J Med Entomol 2007, 44:205-210.

66. Beserra E, Castro F, Santos J, Santos T, Fernandes C: Biologia e exigências térmicas de Aedes aegypti (L.)(Diptera: Culicidae) provenientes de quatro regiões bioclimáticas da Paraíba. Neotrop Entomol 2006, 35:853-860.

67. Arrivillaga J, Barrera R: Food as a limiting factor for Aedes aegypti in water-storage containers. J Vector Ecol 2004, 29:11-20.

68. Bedhomme S, Agnew P, Sidobre C, Michalakis Y: Virulence reaction norms across a food gradient. $P$ Roy Soc Lond B Bio 2004, 271:739-744.

69. Irvin N: Assessing fitness costs for transgenic Aedes aegypti expressing the GFP marker and transposase genes. PNAS USA 2004, 101:891-896.

70. Kamimura K, Matsuse I, Takahashi H, Komukai J, Fokuda T, Suzuki K, Aratani M, Shirai Y, Mogi M: Effect of temperature on the development of Aedes aegypti and Aedes albopictus. Med Entomol Zool 2002, 53:53-58.

71. Lounibus L, Suarez S, Menendez Z, Nishimura N, Escher R, O'Connell S, Rey J: Does temperature affect the outcome of larval competition between Aedes aegypti and Aedes albopictus? J vector Entomol 2002, 27:86-95

72. Tsuda Y, Takagi M: Survival and development of Aedes aegypti and Aedes albopictus (Diptera: Culicidae) larvae under a seasonally changing environment in Nagasaki, Japan. Environ Entomol 2001, 30:855-860.

73. Tun-Lin W, Burkot T, Kay B: Effects of temperature and larval diet on development rates and survival of the dengue vector Aedes aegypti in north Queensland, Australia. Med Vet Entomol 2000, 14:31-37.

74. Costero A, Edman J, Clark G, Kittayapong P, Scott T: Survival of starved Aedes aegypti (Diptera: Culicidae) in Puerto Rico and Thailand. J Med Entomol 1999, 36:272-276.

75. Silva H, Silva I: Influência do período de quiescência dos ovos sobre o ciclo de vida de Aedes aegypti (Linnaeus, 1762)(Diptera, Culicidae) em condições de laboratório. Rev Soc Bras Med Tro 1999, 32:349-355.

76. Thu H, Aye K, Thien S: The effect of temperature and humidity on dengue virus propagation in Aedes aegypti mosquitos. SE Asian J Trop Med 1998, 29:280-284. 
77. Becnel J, Undeen A: Influence of temperature on developmental parameters of the parasite/host system Edhazardia aedis (Microsporida: Amblyosporidae) and Aedes aegypti (Diptera: Culicidae). J Invetebr Pathol 1992, 60:299-303.

78. Rueda L, Patel K, Axtell R, Stinner R: Temperature-dependent development and survival rates of Culex quinquefasciatus and Aedes aegypti (Diptera: Culicidae). J Med Entomol 1990, 27:892-898.

79. Ho B, Ewert A, Chew L: Interspecific competition among Aedes aegypti, Ae. albopictus, and Ae. triseriatus (Diptera: Culicidae): larval development in mixed cultures. J Med Entomol 1989, 26:615-623.

80. Russell R: Larval competition between the introduced vector dengue fever in Australia, Aedes aegypti (L.), and a native container-breeding mosquito, Aedes notoscriptus (Skuse) (Diptera: Culicidae). Aust J Zool 1986, 34:527-534.

81. Soekiman S, Machfudz S, Adipoetro S, Yamanishi H, Matsumura Y: Comparative studies on the biology of Aedes aegypti (Linnaeus, 1762) and Aedes albopictus (Skuse, 1895) in a room condition. ICMR Ann 1984 4:143-151.

82. Dye C: Intraspecific competition amongst larval Aedes aegypti: food exploitation or chemical interference? Ecol Entomol 1982, 7:39-46.

83. Saul S, Novak R, Ross Q: The role of preadult stages in the ecological separation of two subspecies of Aedes aegypti. Am Midl Nat 1980, 104:118-134.

84. Gilpin ME, McClelland GA: Systems analysis of the yellow fever mosquito Aedes aegypti. Fortschr Zool 1979, 25:355-388.

85. Dadd R, Kleinjan R, Sneller V: Development of several species of mosquito larvae in fully defined dietary media: preliminary evaluation. Mosq News 1977, 37:699-703.

86. Lachmajer J, Hien D: Effect of the environmental conditions on eggs and water living stages of Aedes aegypti (Linn.) and Aedes albopictus (Skuse), vectors of dengue haemorrhagic fever in Viet-Nam. Bull Inst Marit Trop Med Gdynia 1975, 26:353-367.

87. Ameen M, Moizuddin M: Duration of the various developmental stages of Aedes aegypti (L) (Diptera: Culicidae) in Dacca City. Dacca University Studies B 1973, 21:15-25.

88. Moore C, Whitacre D: Competition in mosquitoes 2. Production of Aedes-aegypti, Larval growth retardant at various densities and nutrition levels. Ann Entomol Soc Am 1972, 65:915-918.

89. Southwood T, Murdie G, Yasuno M, Tonn R, Reader P: Studies on the life budget of Aedes aegypti in Wat Samphaya, Bangkok, Thailand. Bull World Health Organ 1972, 46:211-226.

90. Rosay B: Comparative growth rates of aquatic stages of ten mosquito species (Diptera: Culicidae) at two constant temperatures. Proc Utah Mosa Abat Assoc 1972, 25:31-44.

91. Nayar JK, Sauerman DM: A comparative study of growth and development in Florida mosquitoes: Part 1: Effects of environmental factors on ontogenetic timings, endogenous diurnal rhythm and synchrony of pupation and emergence. J Med Entomol 1970, 7:163-174.

92. McCray E, Fay R, Schoof H: The bionomics of Landesteria culicis and Aedes aegypti. J Invertebr Pathol 1970, 16:42-53.

93. Keirans J: Larval development of Aedes aegypti (L.) in used auto tires. Mosq News 1969, 29:43-46.

94. Moore C, Fisher B: Competition in mosquitoes: density and species ratio effects on growth, mortality, fecundity, and production of growth retardant. Ann Entomol Soc Am 1969, 62:1325-1331.

95. Peters T, Chevone B, Greenough N, Callahan R, Barbosa P: Intraspecific competition in Aedes aegypti (L.) larvae: I. Equipment, techniques, and methodology. Mosq News 1969, 29:667-674.

96. Brust R: Effect of starvation on molting and growth in Aedes aegypti and A. vexans. J Econ Entomol 1968, 61:1570-1572.

97. Keirans J, Fay R: Effect of food and temperatures on Aedes aegypti (L.) and Aedes triseriatus (Say) larval development. Mosa News 1968, 28:338-341.

98. Wada Y: Effect of larval density on the development of Aedes aegypti (L.) and the size of adults. Quaest Entomol 1965, 1:223-249.

99. Lea A: Some relationships between environment, corpora allata, and egg maturation in Aedine mosquitoes. J Insect Physiol 1963, 9:793-809.

100. Ofuji K: Possibility of establishment of yellow fever mosquito, Aedes aegypti L. in Japan. 2. Cold- and dry-resistance of eggs, ecological zero point of larvae, development of larvae in early spring, and general summary. Endemic Dis Bull Nagasaki Univ 1963, 4:209-222.
101. Christophers S: Aedes aegypti L., the yellow fever mosquito: its life history, bionomics, and structure. London: Cambridge University Press; 1960.

102. Bar-Zeev B: The effect of temperature on the growth rate and survival of the immature stages of Aedes aegypti (L.). Bull Entomol Res 1958, 49:157-163.

103. Headlee TJ: The relative effects on insect metabolism of temperatures derived from constant and variable sources. J Econ Entomol 1940, 33:361-364.

104. Headlee TJ: Further studies of the relative effects on insect metabolism of temperatures derived from constant and variable sources. J Econ Entomol 1941, 34:171-174.

105. Faraway JJ: Extending the linear model with $R$ : generalized linear, mixed effects and nonparametric regression models. Boca Raton, FL: CRC Press; 2006.

106. Pinheiro J, Bates D, Saikat D, Sarkar D, R Core Team: NIme: linear and nonlinear mixed effects models. ; 2013. R package version 3.1-109.

107. R Development Core Team: $R$ : A language and environment for statistical computing. Vienna, Austria: R Foundation for Statistical Computing; 2013. http://www.R-project.org/.

108. Ikemoto T: Intrinsic optimum temperature for development of insects and mites. Environ Entomol 2005, 34:1377-1387.

109. Ikemoto TTK: A new linearized formula for the law of total effective temperature and the evaluation of line-fitting methods with both variable subject to error. Environ Entomol 2000, 29:671-682.

110. Hedges LV, Olkin I: Stasticical methods for meta-analysis. New York: Academic Press, Inc; 1985.

111. Damos P: Temperature-driven models for insect development and vital thermal requirements. Psyche 2012. doi.org/10.1155/2012/123405.

112. Couret J, Dotson EM, Benedict M: Temperature, larval diet, and density effects on development rates and survival of Aedes aegypti (Diptera: Culicidae). PLOS ONE. in press.

113. Barrera R, Amador M, Clark GG: Ecological factors influencing Aedes aegypti (Diptera: Culicidae) productivity in artificial containers in Salinas, Puerto Rico. J Med Entomol 2006, 43:484-492.

114. Dye C: Competition amongst larval Aedes aegypti: the role of interference. Ecol Entomol 1984, 9:355-357.

115. Fitzgerald D, Tipping PW: Effect of insect density and host plant quality on wing-form in Megamelus scutellaris(Hemiptera: Delphacidae). Florida Entomol 2013, 96:124-130.

116. Logan $\mathrm{H}$ : Non-linear models and temperature dependent development in arthropods- a reply to Dr Jerome A. Onsager. Environ Entomol 2011, 12:R5.

117. Kontodimas D, Eliopoulos P, Stathas G, Economou L: Comparative temperature-dependent development of Nephus includens (Kirsch) and Nephus bisignatus (Boheman)(Coleoptera: Coccinellidae) preying on Planococcus citri (Risso)(Homoptera: Pseudococcidae): evaluation of a linear and various nonlinear models using specific criteria. Environ Entomol 2004, 33:1-11.

118. Roltsch WJ, Mayse MA, Clausen K: Temperature-dependent development under constant and fluctuating temperatures: comparison of linear versus nonlinear methods for modeling development of western grapeleaf skeletonizer (Lepidoptera: Zygaenidae). Environ Entomol 1990, 19:1689-1697

119. David J, Gibert P, Gravot E, Petavy G, Morin J, Karan D, Moreteau B: Phenotypic plasticity and developmental temperature in Drosophila: analysis and significance of reaction norms of morphometrical traits. J Therm Biol 1997, 22:441-451.

120. Arnold CY: The determination and significance of the base temperature in a linear heat unit system. Am Soc Hort Sci 1959, 74:430-445.

121. Jarosík V, Honek A, Dixon AFG: Developmental rate isomorphy in insects and mites. Am Nat 2002, 160:497-510.

122. Briere J-F, Pracros P, Le Roux A-Y, Pierre J-S: A novel rate model of temperature-dependent development for arthropods. Environ Entomol 1999, 28:22-29.

123. Richardson K, Hoffmann AA, Johnson P, Ritchie S, Kearney MR: Thermal sensitivity of Aedes aegypti from Australia: empirical data and prediction of effects on distribution. J Med Entomol 2011, 48:914-923.

124. Pradhan S: Insect population studies II. Rate of insect develoment under variable temperatures of the field. Proc Nat Inst Sci India 1945, 11:74-80.

125. Yang HM, Macoris MLG, Galvani KC, Andrighetti MTM, Wanderley DMV: Assessing the effects of temperature on the population of Aedes aegypti, the vector of dengue. Epidemiol Infect 2009, 137:1188-1202. 
126. Sharpe PJH, Curry GL, DeMichele DW, Cole CL: Distribution model of organism development times. J Theor Biol 1977, 66:21-38.

127. Sharpe $P, H u L:$ Reaction kinetics of nutrition dependent poikilotherm development. J Theor Biol 1980, 82:317-333.

128. Curry GL: Foundations of stochastic development. J Theor Bio/ 1978, 74:397-410.

129. Hagstrum DW, Workman E: Interaction of temperature and feeding rate in determining the rate of development of larval Culex tarsalis (Diptera, Culicidae). Ann Entomol Soc Am 1971, 64:668-671.

130. Carrington LB, Seifert SN, Willits NH, Lambrechts L, Scott TW: Large diurnal temperature fluctuations negatively influence Aedes aegypti (Diptera: Culicidae) life-history traits. J Med Entomol 2013, 50:43-51.

131. Carrington LB, Seifert SN, Armijos MV, Lambrechts L, Scott TW: Reduction of Aedes aegypti vector competence for dengue virus under large temperature fluctuations. Am J Trop Med Hyg 2013, 88:689-697.

132. Paaijmans K, Imbahale S, Thomas M, Takken W: Relevant microclimate for determining the development rate of malaria mosquitoes and possible implications of climate change. Malar J 2010, 9:196.

133. Lambrechts L, Paaijmans KP, Fansiri T, Carrington LB, Kramer LD, Thomas $M B$, Scott TW: Impact of daily temperature fluctuations on dengue virus transmission by Aedes aegypti. PNAS USA 2011, 108:7460-7465.

134. Carrington LB, Armijos MV, Lambrechts L, Barker CM, Scott TW: Effects of fluctuating daily temperatures at critical thermal extremes on Aedes aegypti life-history traits. PLOS ONE 2013, 8:e58824.

135. Huffaker CB: The temperature relations of the immature stages of the malarial mosquito, Anopheles quadrimaculatus Say, with a comparison of the developmental power of constant and variable temperatures in insect metabolism. Ann Entomol Soc Am 1944, 37:1-27.

136. Joshi D: Effect of fluctuating and constant temperatures on development, adult longevity and fecundity in the mosquito Aedes krombeini. J Therm Biol 1996, 21:151-154.

137. Lounibos L, Suárez S, Menéndez Z, Nishimura N, Escher RL, O'Connell SM, Rey JR: Does temperature affect the outcome of larval competition between Aedes aegypti and Aedes albopictus? J Vector Ecol 2002 27:86-95.

138. Murrell EG, Damal K, LOUNIBOS LP, Juliano SA: Distributions of competing container mosquitoes depend on detritus types, nutrient ratios, and food availability. Ann Entomol Soc Am 2011, 104:688-698.

139. Murrell EG, Juliano SA: Detritus type alters the outcome of interspecific competition between Aedes aegypti and Aedes albopictus (Diptera: Culicidae). J Med Entomol 2008, 45:375-383.

140. Bochdanovits Z: Temperature dependent larval resource allocation shaping adult body size in Drosophila melanogaster. J Evol Biol 2003, 16:1159-1167.

141. Ghosh SM, Testa ND, Shingleton AW: Temperature-size rule is mediated by thermal plasticity of critical size in Drosophila melanogaster. Proc $R$ Soc B 2013, 280:1471-1471.

142. Mori A, Oda T, Zaitsu M, Ueda M: Studies on the developing period of larval stage of the Culex pipiens complex in Japan. Trop Med 1988, 30:155-161.

143. Olanratmanee P, Kittayapong P, Chansang C, Hoffmann AA, Weeks AR, Endersby NM: Population genetic structure of Aedes (Stegomyia) aegypti (L.) at a micro-spatial scale in Thailand: implications for a dengue suppression strategy. PLoS Negl Trop Dis 2013, 7:e1913.

144. Endersby NM, Hoffmann AA, White VL, Ritchie SA, Johnson PH, Weeks AR: Changes in the genetic structure of Aedes aegypti (Diptera: Culicidae) populations in Queensland, Australia, across Two seasons: implications for potential mosquito releases. J Med Entomol 2011, 48:999-1007.

145. Smith CC, Fretwell SD: The optimal balance between size and number of offspring. Am Nat 1974, 108:499-506.

146. Fox C, Czesak M: Evolutionary ecology of progeny size in arthropods. Annu Rev Entomol 2000, 45:341-369.

147. Muturi EJ, Blackshear M, Montgomery A: Temperature and density-dependent effects of larval environment on Aedes aegypti competence for an alphavirus. J Vector Ecol 2012, 37:154-161.

148. Muturi EJ, Alto BW: Larval environmental temperature and insecticide exposure alter Aedes aegypti competence for arboviruses. Vector-Borne Zoonot 2011, 11:1157-1163.

149. Carriere Y, Roff DA: The evolution of offspring size and number: a test of the Smith-Fretwell model in three species of crickets. Oecologia 1995, 102:389-396.
150. Messina FJ, Fox CW: Offspring size and number. In Evolutionary ecology: concepts and case studies. Edited by Fox CW, Roff DA, Fairbairn DJ. Oxford, UK: Oxford University Press; 2001:113-127.

151. Maciel-De-Freitas R, Codeço CT, Lourenço-De-Oliveira R: Body size-associated survival and dispersal rates of Aedes aegypti in Rio de Janeiro. Med Vet Entomol 2007, 21:284-292.

152. Alto BW, Reiskind MH, Lounibos LP: Size alters susceptibility of vectors to dengue virus infection and dissemination. Am J Trop Med Hyg 2008, 79:688-695.

153. Schneider JR, Morrison AC, Astete H, Scott TW, Wilson ML: Adult size and distribution of Aedes aegypti (Diptera: Culicidae) associated with larval habitats in Iquitos, Peru. J Med Entomol 2004, 41:634-642.

154. Alto B, Lounibos L, Higgs S, Juliano SA: Larval competition differentially affects arbovirus infection in Aedes mosquitoes. Ecology 2005, 86:3279-3288.

155. Depinay J, Mbogo C, Killeen G, Knols B, Beier J, Carlson J, Dushoff J, Billingsley P, Mwambi H, Githure J: A simulation model of African Anopheles ecology and population dynamics for the analysis of malaria transmission. Malar J 2004, 3:29.

doi:10.1186/1472-6785-14-3

Cite this article as: Couret and Benedict: A meta-analysis of the factors influencing development rate variation in Aedes aegypti (Diptera: Culicidae). BMC Ecology 2014 14:3.

\section{Submit your next manuscript to BioMed Central and take full advantage of:}

- Convenient online submission

- Thorough peer review

- No space constraints or color figure charges

- Immediate publication on acceptance

- Inclusion in PubMed, CAS, Scopus and Google Scholar

- Research which is freely available for redistribution 